\title{
Laser ignition of dust clouds
}

\author{
Ch. PROUST
}

INERIS, BP. 2, F-60550 Verneuil-en-Halatte 


\begin{abstract}
In a previous paper [1], the possibility of igniting a combustible dust-air mixtures by a light beam in contact with a substrate made of an inert matter and heated by a light beam was investigated. The objective of the present work is to produce more data on the subject.The available results suggest a strong similarity between combustible dust-air mixtures and explosible gas-air mixtures within the scope of the investigated ignition phenomena. In particular a relationship between the standard ignition temperature of dust clouds and the temperature of the target at the minimum incident power at ignition (continuous irradiation) has been highlighted which seems to be similar to the one obtained for gases. If confirmed, this would imply that the knowledge of these standard parameters would help in predicting the danger of igniting any kind of explosible mixtures including hybrid mixtures (combustible gas-combustible dust-air) or oxygen depleted/enriched mixtures.
\end{abstract}

\title{
1. INTRODUCTION
}

In a previous paper [1], the possibility of igniting a combustible dust-air mixtures by a light beam in contact with a substrate made of an inert matter and heated by a light beam was investigated. Ignition with a light beam simply crossing the suspension without other obstacle on the path was achieved but was nevertheless difficult. Ignition was much easier when the beam impinged on a target placed into the suspension. Much of the effort has been spent in preparing the various experimental configurations enabling the underlying physics to be investigated. The quantity of data obtained so far was however limited. The objective of the present work is to produce more quantitative data, helpful for standards.

The main objective is to find out the thresholds for ignition of representative dust-air mixtures when a light beam is being trapped on a target. The variable parameters are the size of the beam, the nature of the particles, the nature of the target (made of an inert or burnable material) and the duration of the irradiation.

\section{EXPERIMENTAL DETAILS}

\subsection{Setup}

The setup is different from the previous one [1] although based on the same working principles (fluidized bed, dust collector). It consists (figure 1) mainly of a small vertical circular glass column (length : $0.5 \mathrm{~m}$, inner diameter $0.1 \mathrm{~m}$ ). The cloud is being continuously supplied by the fluidized bed of particles at a very low speed (less than $0.5 \mathrm{~m} / \mathrm{s}$ ) inside the column during the irradiation of the target. The suspension could be maintained at a constant concentration during very long time (more than 2 minutes if required). 
The target material (to be irradiated) is slightly packed inside a small insulating cavity (inner diameter 1 $\mathrm{cm}$ ) so as to form a flat vertical surface (figure 2).

The light source is a Nd-YAG laser with a max output of $60 \mathrm{~W}$ operating at $1064 \mathrm{~nm}$. The duration of the irradiation may be controlled. The nominal diameter of the beam is $4 \mathrm{~mm}$ but can be focussed or enlarged by lenses arrangement.

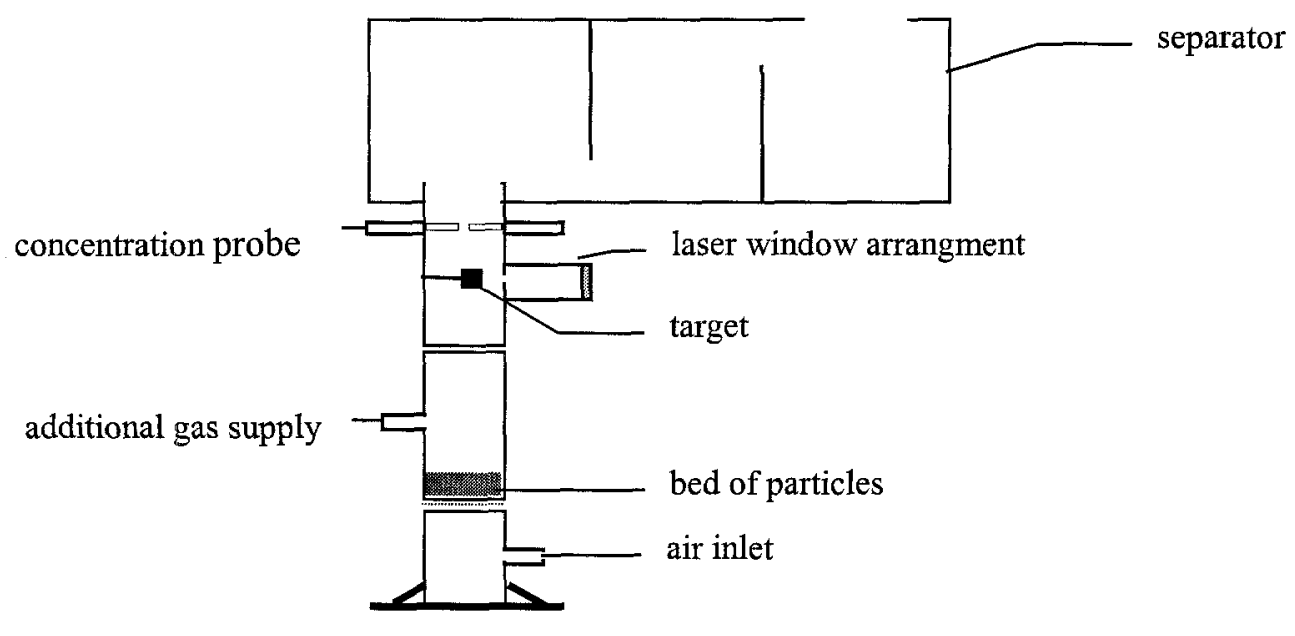

Figure 1: Sketch of the setup

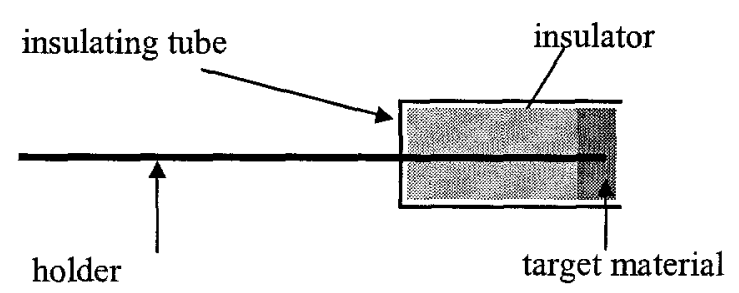

Figure 2: Target arrangement

\subsection{Measurement techniques}


A special optical probe has been designed to allow a direct monitoring of the dust concentration. The principle is based on the attenuation of a light beam accross a cloud of particles. The probe simply consists of a lamp and of a collimated photodiode. In order to check the reliability of the technique, tests were performed during which the attenuation of the beam was measured independently from the mass concentration derived from the simultaneaous measurement of the air flowrate through the tube and of the decrease of mass of the bed of particles. The results are presented on figure 3 , together with theoretical predictions. It appears that the agreement with the theory is reasonable. Furthermore, analysis of such data revealed that the global accuracy of the determination of the mass concentration with this optical technique is about 10 to $20 \%$ in the range $100-1000 \mathrm{~g} / \mathrm{m}^{3}$.

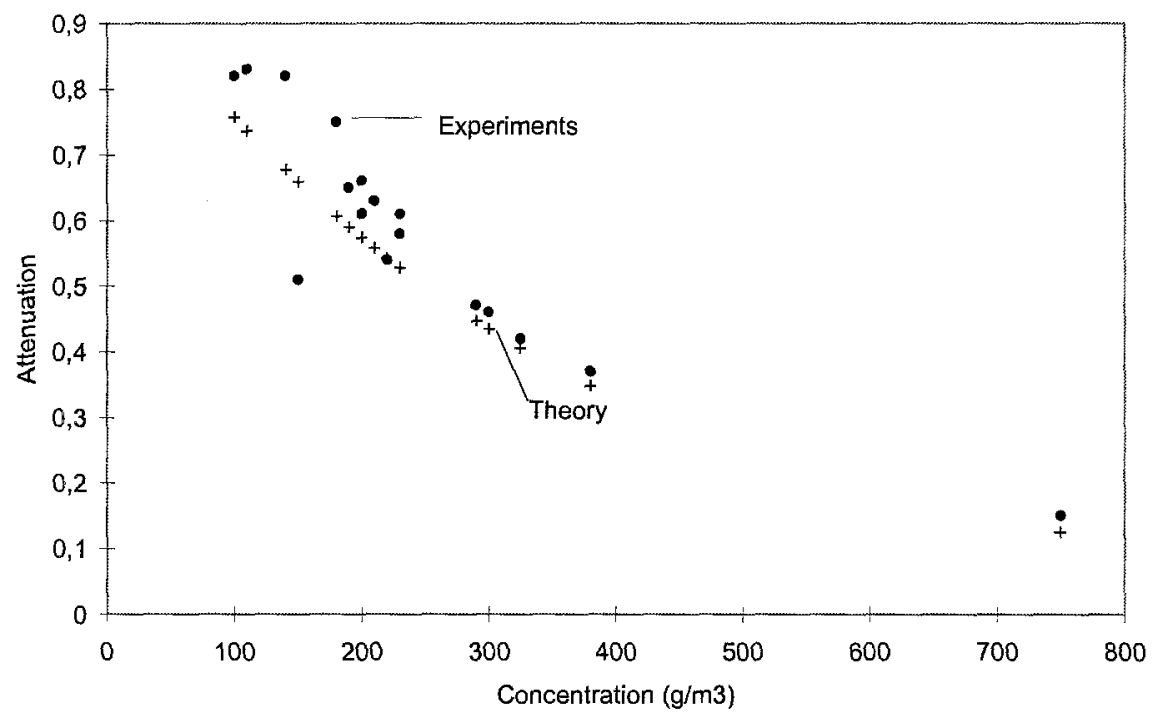

Figure 3: Attenuation as function of the mass particle concentration in the cloud (starch particles)

Temperature measurements of the hot spot on the target have been performed with classical pyrometers. Video records were also performed.

\section{PROPERTIES OF THE REACTIVE DUSTS}

The combustible particles in the clouds should be representative of what can be found in the industry and cover a sufficiently wide spectrum in terms of ignition properties. It appeared desirable to test dusts coming from the food, wood, energy, metal, chemical, pharmaceutical industries. The chosen dusts should cover the spectrum of ignition sensitivity as determined by classical means such as the GodbertGreenwald furnace and the Hartmann apparatuses [2].

The main properties of the selected reactive dusts are presented in table 1. 
Table 1: Combustible dusts tested (particle diameter =sauter mean)

\begin{tabular}{|l|l|l|l|l|l|l|}
\hline Nature of the dust & food & wood & energy & chemistry & chemistry & metallurgy \\
\hline Name & starch & lycopodium & lignite & sulfur & ABS & aluminum \\
\hline Particle size (mm) & 36 & 30 & 17 & 48 & 15 & 15 \\
\hline $\begin{array}{l}\text { Godbert-Greenwald } \\
\text { furnace ignition } \\
\left.\text { temperature( }{ }^{\circ} \mathrm{C}\right)\end{array}$ & 440 & 420 & 500 & 220 & 480 & $(600)$ \\
\hline $\begin{array}{l}\text { Hartmann Ignition } \\
\text { Energy (mJ) }\end{array}$ & $>1200$ & 36 & $>1200$ & 16 & 11 & 65 \\
\hline $\begin{array}{l}\text { Absolute minimum } \\
\text { Ignition Energy (mJ) }\end{array}$ & 10 & $\mathrm{nd}$ & $\mathrm{nd}$ & $<5$ & $\mathrm{nd}$ & $\mathrm{nd}$ \\
\hline $\begin{array}{l}\text { Quenching distance } \\
\text { (mm) }\end{array}$ & 7 & nd & nd & nd & nd & nd \\
\hline Burning velocity $(\mathrm{m} / \mathrm{s})$ & 0.2 & 0.47 & nd & 0.23 & nd & 0.25 \\
\hline
\end{tabular}

\section{THERMAL PROPERTIES OF THE TARGETS}

The coating of the target should be inert or reactive. In the latter case, the practical situation is that the particles on the target and in the cloud are similar.

For the inert situation, the optimum situation is sought in terms of absorptivity. Direct measurements [3] suggested that iron oxide $\left(\mathrm{Fe}_{3} \mathrm{O}_{4}\right)$ had the highest absorptivity between 90 and $100 \%$. Maximum surface temperature of more than $1400^{\circ} \mathrm{C}$ could be obtained.

When the target is reactive, a combustion may be initiated on the surface of the target. A further point concerns the absorptivity of the material of the target. The results [3] are presented in table 2 together with the ignition threshold of the coating. It needs to be pointed out that sulfur coatings could not be ignited. They fuse and vaporise.

Table 2 : Ignition threshold of target material (unexpanded Nd-YAG CW laser beam)

\begin{tabular}{|l|l|l|l|l|l|l|}
\hline Dust & Starch & Sulfur & $\begin{array}{l}\text { Lycopod } \\
\mathrm{e}\end{array}$ & ABS & Lignite & Aluminum \\
\hline Threshold $(\mathrm{mW})$ & 1900 & none & 14200 & 9050 & 4070 & 4500 \\
\hline Absortivity $(\%)$ & 12 & & 2.5 & 3 & 60 & 33 \\
\hline
\end{tabular}




\section{CONTINUOUS IRRADIATION}

\subsection{Inert targets}

A typical example is presented on figure 4.

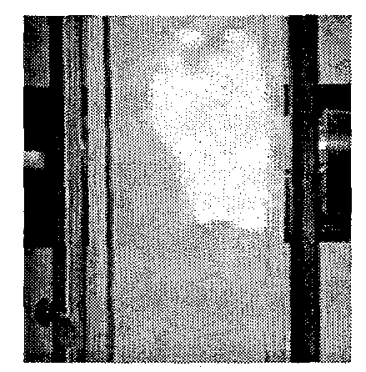

Figure 4 : Ignition of a starch dust air mixture by a CW-MM-Nd-YAG laser beam

There is a clear incidence of the mass particle concentration upon the ignition threshold (figure 5). The threshold diminishes as the concentrations increases and then a plateau is found beginning at 500 to 700 $\mathrm{g} / \mathrm{m}^{3}$ ( 2 to 3 times the stoechiometry). The power is referred as the amount of radiation reaching the surface of the target.

This results seems coherent with those obtained with premixed gases [3].

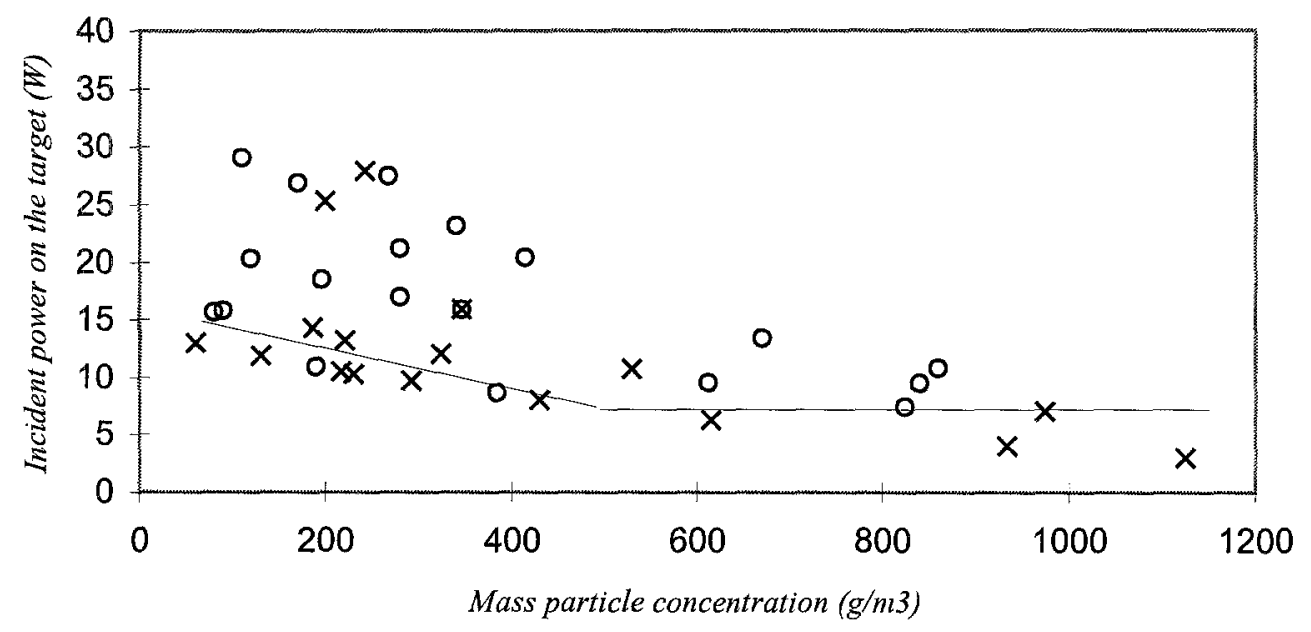

Figure 5: Critical ignition power of starch dust-air suspensions by an enlarged CW-MM- Nd-YAG laser beam (enlargment X 2; target $\mathrm{Fe}_{3} \mathrm{O}_{4}$ ): circles mean "ignition" 
On figure 6, the evolution of the minimum ignition power for starch dust-air suspensions is presented as function of the beam size (modified with lenses). It appears clearly that, under the present experimental conditions, the minimum value is obtained when the optical beam diameter is between 2 and $4 \mathrm{~mm}$ (hot spot size of 3 to $5 \mathrm{~mm}$ ). For sulfur, the minimum power is reached when the optical beam diameter is between 1 and $2 \mathrm{~mm}$ (hot spot size of $3 \mathrm{~mm}$ ).

For very small beams (focussed) the target appears seriously disturbed by the beam and a hole is instantaneously drilled into the target at the hot spot. It is believed that this limits the amount of heat tranferred to the suspensions and renders ignition less probable.

Apart from this last point, the general behaviour of the reactive mixture when the hot spot size increases seems comparable to that of premixed gases (see other contributions) : when the spot size diminishes, the critical power for ignition decreases down to a limit reached as soon as the spot size is below some limit, presumably the minimum flame kernel diameter. For the specific case suspensions, the minimum flame kernel diameters have been estimated previously ([4]) to be of the order of $7 \mathrm{~mm}$ for starch and less for sulfur.

Subsequently, the laser has been used without any lens on the path of the beam. In this situation and for the range of critical power obtained for ignition, the hot spot size was of the order of $4 \mathrm{~mm}$. Such circumstances allow a good estimate of the absolute power required for ignition and not of the critical irradiance which is the relevant parameter when the hot spot size is above the minimum flame ball diameter. Nevertheless estimates of the critical irradiance have been attempted based on the measurements (power/beam area). Apart from the specific case of sulfur dust, these data are likely to be conservative by a factor of at least 2 .

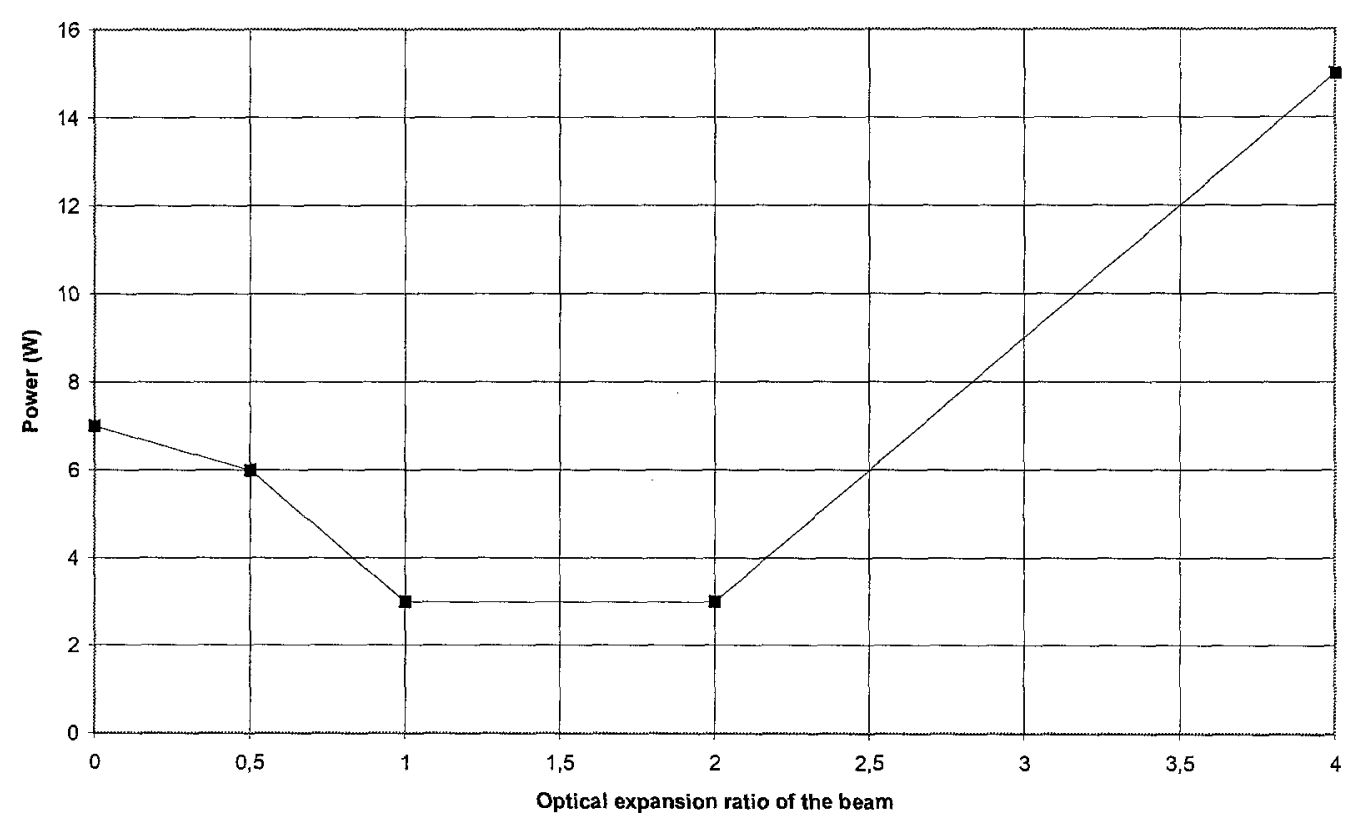

Figure 6 : Minimum ignition power as function of beam size ( $\mathrm{CW} \mathrm{Nd-YAG,} \mathrm{starch} \mathrm{dust-air} \mathrm{suspension,} \mathrm{target:} \mathrm{Fe}_{3} \mathrm{O}_{4}$ )

Given the foregoing precautions, the critical powers for ignition and estimated irradiances are presented in table 3. 
Table 3 : Summary of Tests results obtained with an inert target

\begin{tabular}{|l|l|l|l|l|l|l|}
\hline Dust & Starch & Sulfur & Lignite & ABS & Lycopodium & Aluminum \\
\hline $\begin{array}{l}\text { Sauter mean } \\
\text { dia. }\end{array}$ & $36 \mu \mathrm{m}$ & $48 \mu \mathrm{m}$ & $17 \mu \mathrm{m}$ & $15 \mu \mathrm{m}$ & $30 \mu \mathrm{m}$ & $15 \mu \mathrm{m}$ \\
\hline Conc. range & 100 to $1400 \mathrm{~g} / \mathrm{m}^{3}$ & 100 to $1000 \mathrm{~g} / \mathrm{m}^{3}$ & 100 to $900 \mathrm{~g} / \mathrm{m}^{3}$ & 30 to $700 \mathrm{~g} / \mathrm{m}^{3}$ & 30 to $700 \mathrm{~g} / \mathrm{m}^{3}$ & 40 to $500 \mathrm{~g} / \mathrm{m}^{3}$ \\
\hline Critical power & $2700 \mathrm{~mW}$ & $1200 \mathrm{~mW}$ & $2500 \mathrm{~mW}$ & $5300 \mathrm{~mW}$ & $4000 \mathrm{~mW}$ & $/$ \\
\hline $\begin{array}{l}\text { Critical } \\
\text { irradiance }\end{array}$ & $<200 \mathrm{~mW} / \mathrm{mm}^{2}$ & $100 \mathrm{~mW} / \mathrm{mm}^{2}$ & $<200 \mathrm{~mW} / \mathrm{mm}^{2}$ & $<400 \mathrm{~mW} / \mathrm{mm}^{2}$ & $<300 \mathrm{~mW} / \mathrm{mm}^{2}$ & $/$ \\
\hline $\begin{array}{l}\text { Ignition } \\
\text { temperature } \\
\text { on the target }\end{array}$ & $800^{\circ} \mathrm{C}$ & $730^{\circ} \mathrm{C}$ & $780^{\circ} \mathrm{C}$ & $930{ }^{\circ} \mathrm{C}$ & $890^{\circ} \mathrm{C}$ & $/$ \\
\hline
\end{tabular}

Since the ignition delays are typically of the order of seconds or tens of seconds, it is clear that the ignition mechanisms pertain to category of "hot surface" ignition. It is usually admitted that the characteristic standard ignition parameter attached to this phenomenology is the ignition temperature measured in a furnace such as the Godbert-Greenwald apparatus. The size of this latter and experimental procedure is rather similar to the device classically used to measure the "autoignition temperatures " for combustible gases and vapours. A tentative correlation between these standard values and the ignition temperature derived from the data of table 3 are shown of figure 7. A reasonable correlation appears which, morever, seems very similar to the one obtained for combustible gas-air mixtures.

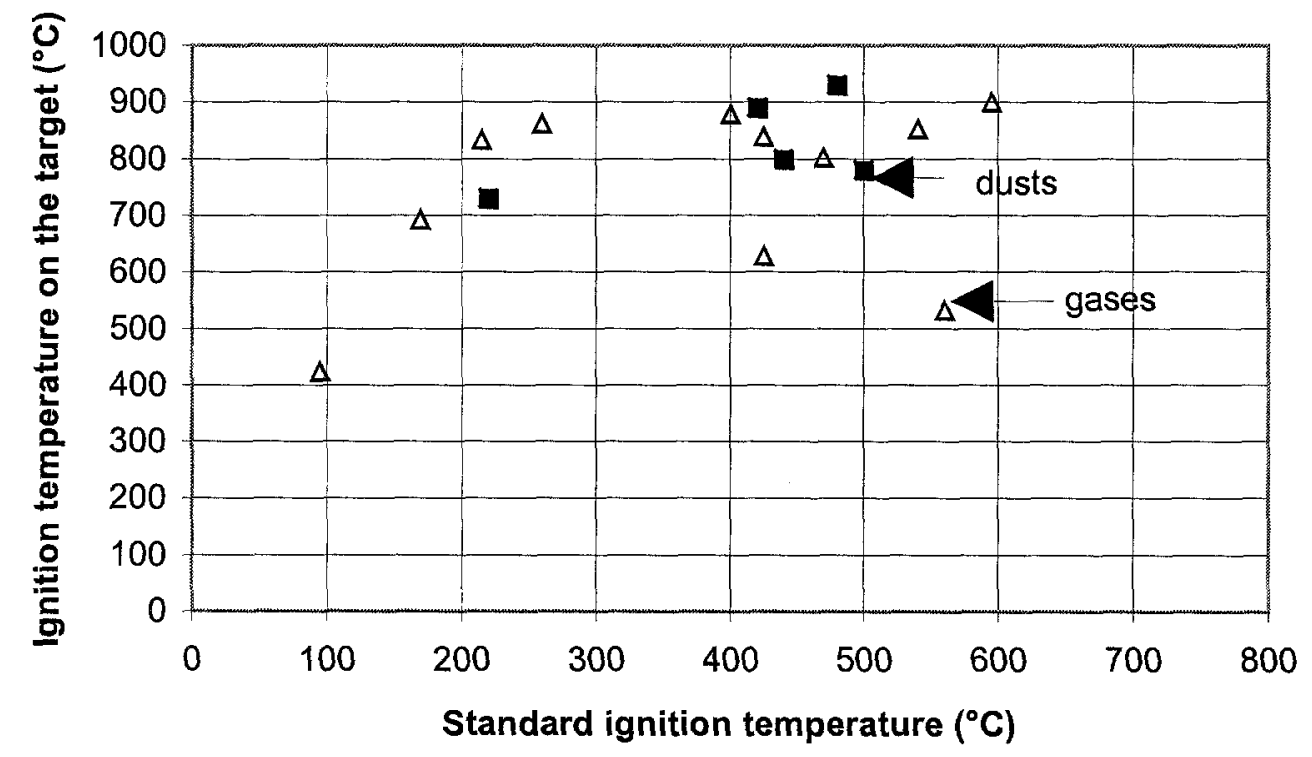

Figure 7 : Tentative correlation between the standard ignition temperature (Godbert - Greeenwald furnace) and the ignition temperature on the irradiated target

\subsection{Reactive targets}

As compared to the "inert target" case, successive "flashes" are detected on the target which do not always lead to an ignition. This confirms previous observations [1]. 
Because of the relatively large heat up durations, a significant number of ignitions could only be obtained with the beam focussed on the target. The data suggest (figure 8) that the curve representing the minimum ignition power as function of the concentration of particles in the cloud is similar to that obtained with the inert target.

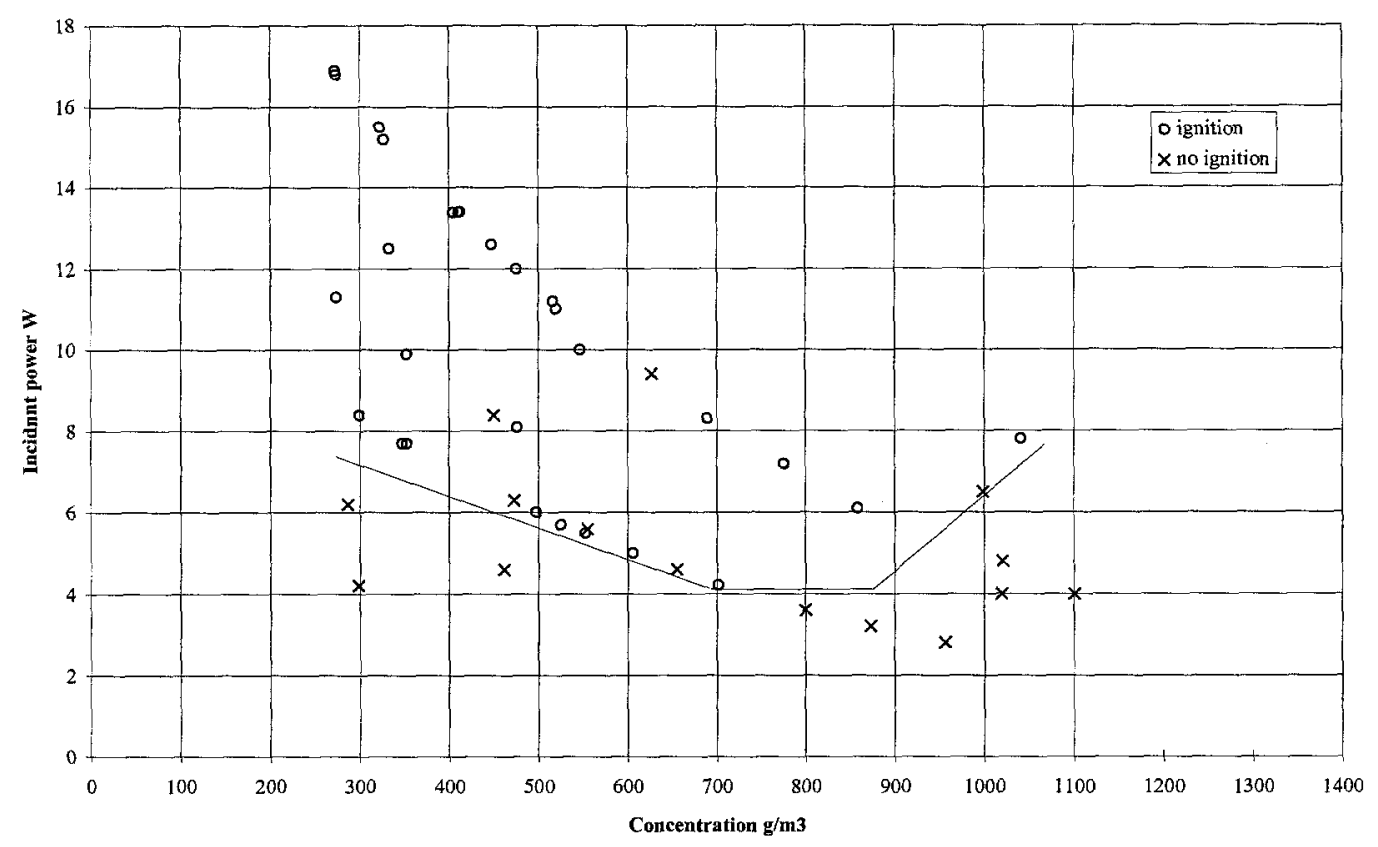

Figure 8: critical ignition power of starch dust-air suspensions by a focussed CW Nd-YAG laser beam (target starch)

Tests have been performed with the most absorbing reactive target materials : starch and lignite. Minimum ignition thresholds are of the order of $4000 \mathrm{~mW}$ for starch dust clouds and 2500 to $4000 \mathrm{~mW}$ for lignite dust clouds. Comparison with the non-reactive situation (table 4) reveals that the present " inert" situation seems to offer the practical worst case situation. The reactivity of the target does not seem to play a dominant role in the present situation. A justification might be sought in the comparison of the data from table 2 and 4 where it appears that the initiation of the combustion of the reactive target happens at a higher or comparable power than the combustion of the cloud.

Table 4 : Comparison of inert and reactive case

\begin{tabular}{|l|l|l|l|l|l|l|}
\hline Dust & Starch & Starch & none & Lignite & Lignite & none \\
\hline Target. & $\mathrm{Fe}_{3} \mathrm{O}_{4}$ & Starch & Starch & $\mathrm{Fe}_{3} \mathrm{O}_{4}$ & lignite & lignite \\
\hline Conc. range & $\begin{array}{l}100 \text { to } 1000 \\
\mathrm{~g} / \mathrm{m}^{3}\end{array}$ & $\begin{array}{l}100 \text { to } 1000 \\
\mathrm{~g} / \mathrm{m}^{3}\end{array}$ & $/$ & $\begin{array}{l}100 \text { to } 900 \\
\mathrm{~g} / \mathrm{m}^{3}\end{array}$ & $\begin{array}{l}100 \text { to } 900 \\
\mathrm{~g} / \mathrm{m}^{3}\end{array}$ & $/$ \\
\hline $\begin{array}{l}\text { Critical } \\
\text { power }\end{array}$ & $2700 \mathrm{~mW}$ & $4000 \mathrm{~mW}$ & $1900 \mathrm{~mW}$ & $2500 \mathrm{~mW}$ & $\begin{array}{l}2500 \quad \text { to } \\
4000 \mathrm{~mW}\end{array}$ & $4070 \mathrm{~mW}$ \\
\hline
\end{tabular}




\section{PULSED LIGHT}

For "short" irradiation times, a "spark" type of ignition is expected without any role played by the natural convection as compared to the previous situation. The characteristic property of interest concerning the laser may be the energy in each pulse.

In this situation, it is expected that the ignition process would show similarities with electrical spark ignition. Precise measurements have shown that the minimum ignition energy by electrical spark of dusts like starch would be of the order $10 \mathrm{~mJ}$ [4].

The selected combustible dusts are starch and sulfur which are thought to be two extremes with respect to their sensitivity towards electrical spark ignition. The clouds were submitted to a continuous beam of small dimension (smaller than the quenching distance) until ignition. Photodiodes were used to control the time when the beam appeared and when the flame occurred. The ignition time lag is the difference in time between both events and the ignition energy is defined as the product between this laps of time and the incident power on the target. Energy-time curves for various particle concentrations in the clouds could then be traced (figure 9).

Each curve seems statistically linear and the intercept on the ordinate of the graph may be defined as the minimum ignition energy for very short pulses. The evolution of this factor against particle concentration is shown on figure 10 .

It appears very clearly that a minimum is found for near stoichiometric mixtures $\left(250 \mathrm{~g} / \mathrm{m}^{3}\right)$ as expected for spark ignition theories. Similar trends were found (figure 11) for sulfur except that the minimum for ignition energy on the energy-time graph were not found for zero irradiation time duration but for a duration of 1.5 second.

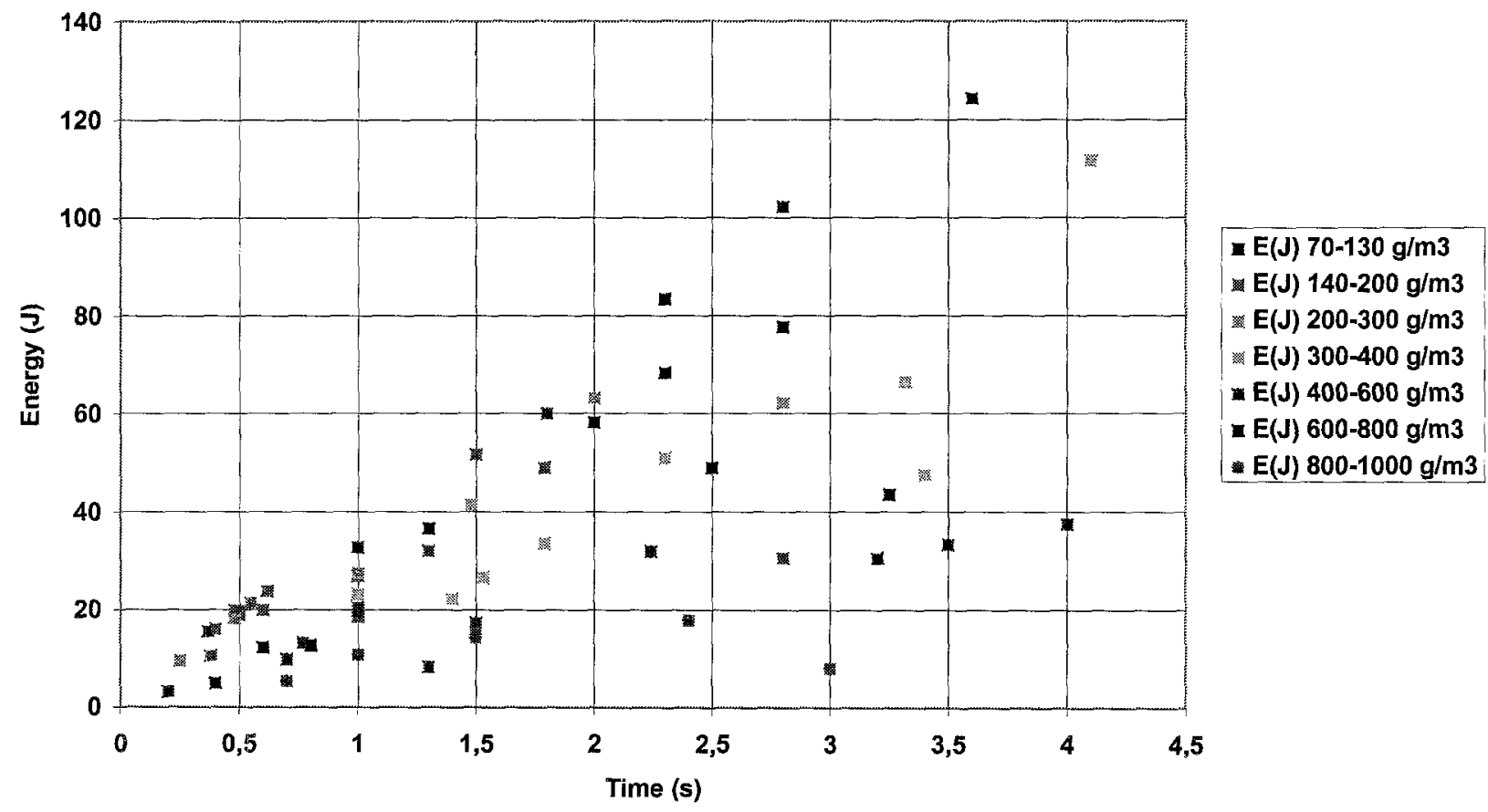

Figure 9 : Energy-time evolutions for starch particle-air clouds (inert target) 


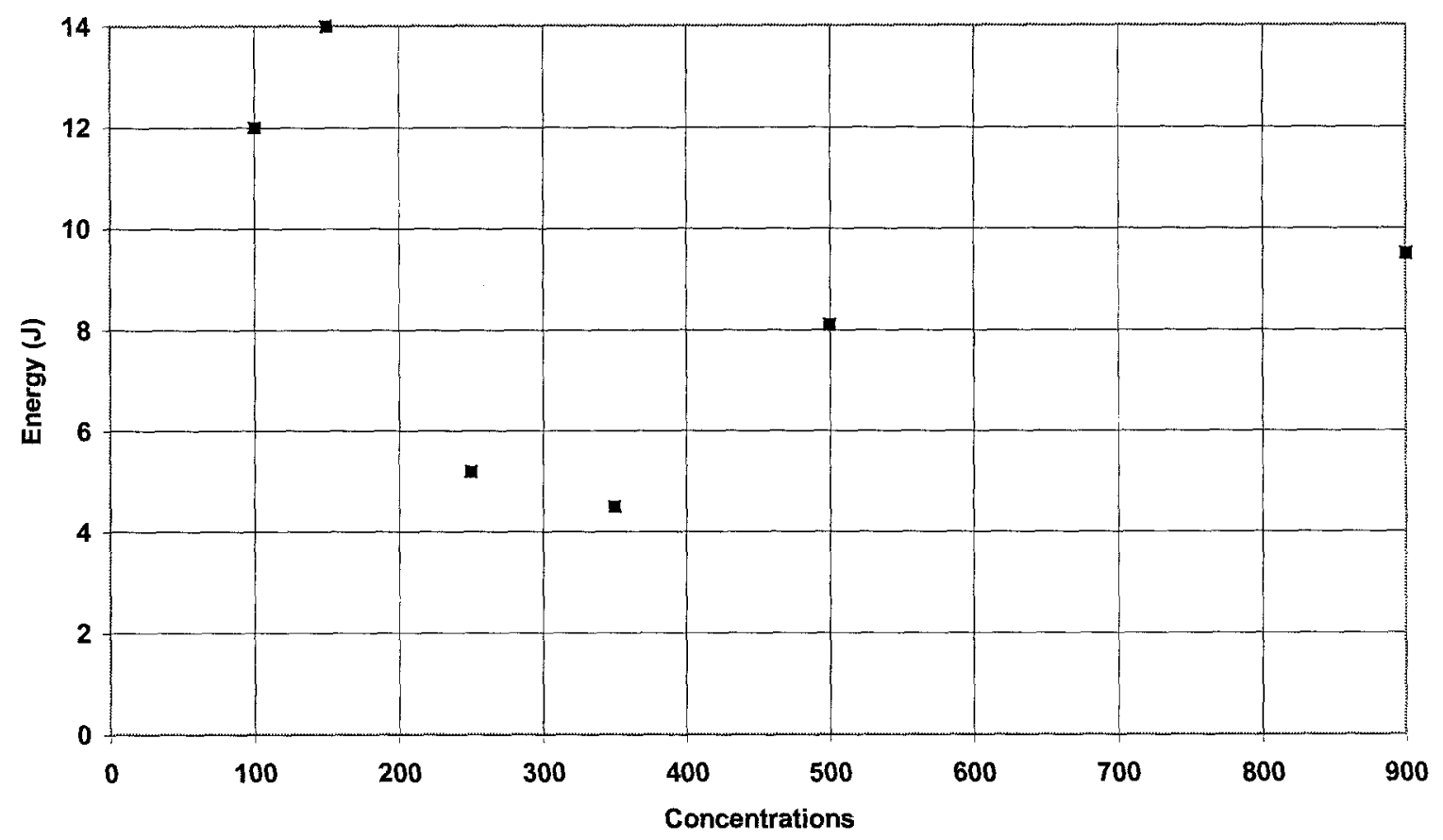

Figure 10 : Minimum energy-concentration evolution for starch particle-air clouds (inert target)

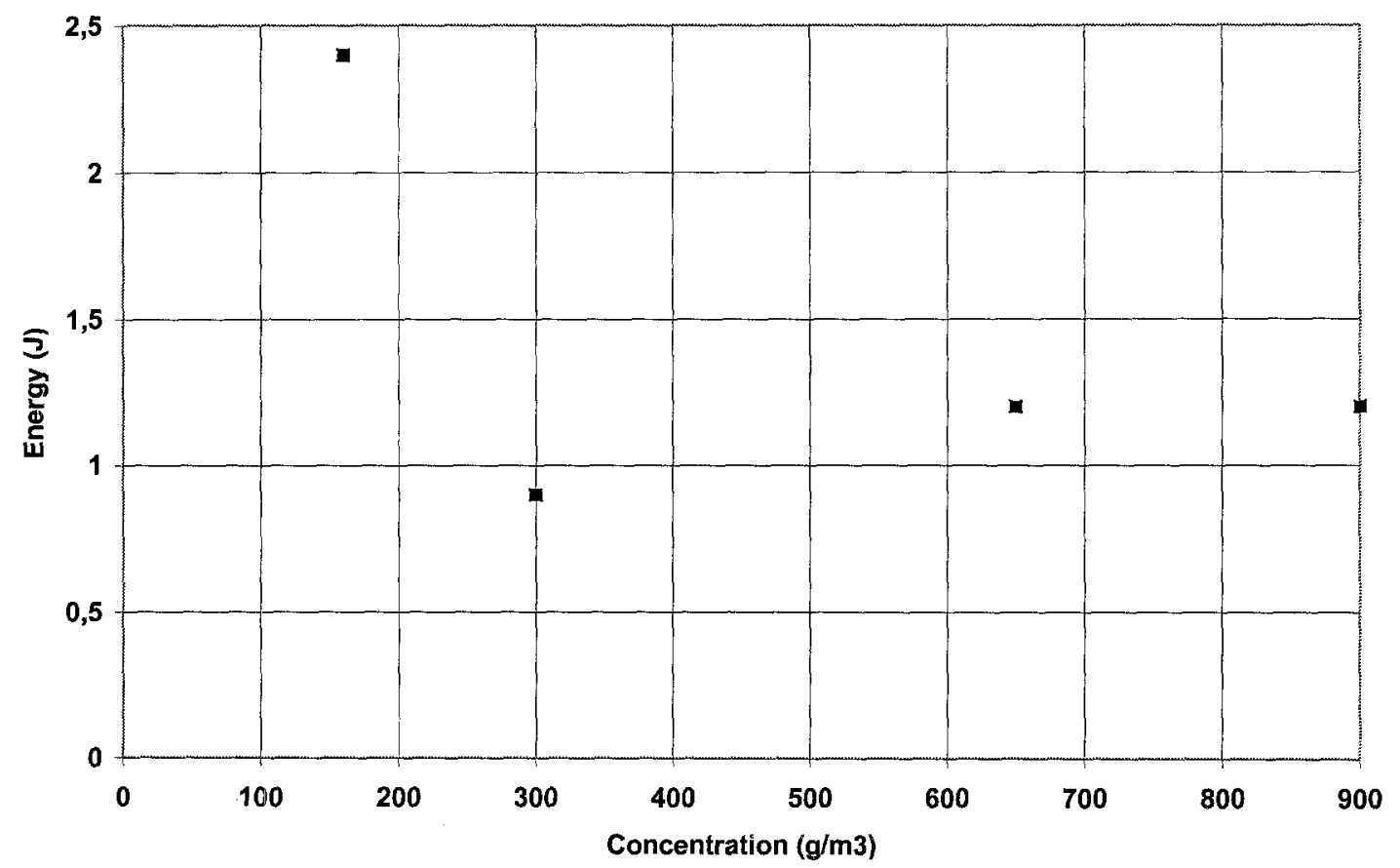

Figure 11 : Minimum energy-concentration evolution for sulfur particle-air clouds (inert target) 
These minima are respectively 4.5 and 0.9 respectively for starch and sulfur. These values are well in excess of the minimum electrical spark ignition ( roughly $10 \mathrm{~mJ}$ if one refers to real values and not on standard parameters). To understand this difference, it may be recalled that the energy of the laser has to be firstly absorbed by the target and tranformed into heat before being diffused into the explosible atmosphere. Since the heat diffusivity of a solid target is greater by one or two order of magnitude from that of gases, it turns out that the ratio of the heat diffused into the target to that transmitted to the atmosphere during the same period would be extremely large. It seems then logical that the minimum ignition energy (by a light pulse) should be much larger than the minimum electrical spark ignition energy. This reasoning also suggests the incidence of the target on this difference and underlines that it may be difficult to give absolute figures, target independent.

\section{CONCLUSION}

The available data presently available suggests a strong similarity between combustible dust-air mixtures and explosible gas-air mixtures within the scope of the investigated ignition phenomena.

In particular a relationship between the standard ignition temperature of dust clouds and the temperature of the target at the minimum incident power at ignition (continuous irradiation) has been highlighted which seems to be similar to the one obtained for gases [2]. If confirmed, this would imply that the knowledge of these standard parameters would help in predicting the danger of igniting any kind of explosible mixtures including hybrid mixtures (combustible gas-combustible dust-air) or oxygen depleted/enriched mixtures.

\section{Acknowlegments}

The author is grateful to The French Ministry for Environment and to the European Union for sponsoring this work.

\section{References}

1. Ch. Proust, in Archivum Combustionis, vol. 17, pp. 7-18, (1997)

2. F. Carleton, H. Bothe, S. Hawksworth, Ch. Proust, Final report of PROPEX, E.U. Report EUR 19617, (1999)

3. Ch. Proust, M. Boudalaa, "Inflammation des nuages de poussières par des étincelles et des surfaces chauffées ", in proceedings of Congrès de Génie des Procédés, Nancy, (Octobre 2001)

4. Ch. Proust, "Flame Kernel development around an electrical sprak in dust-zair mixtures", Poster Presented at the 24th symp on Combustion, Edinburg, (August 2000) 